\title{
PENERAPAN SIKAP PERAWAT DALAM PELAKSANAAN LANGKAH-LANGKAH MENUJU KESELAMATAN PASIEN
}

\author{
Muhaini Atmayana Purba / 181101131 \\ muhainipurba21@gmail.com
}

\begin{abstract}
ABSTRAK
Latar belakang : Keselamatan pasien merupakan sesuatu yang jauh lebih penting dalam pelaksanaan langkah-langkah keselamatan pasien dan perilaku dengan kemampuan perawat sangat berperan penting di dalamnya. Tujuan : Tujuan penulisan ini yaitu mengidenifikasi penerapan sikap perawat dalam pelaksanaan langkah-langkah meuju keselamatan pasien. Metode : Metode yang digunakan merupakan literatur review atau suatu perbandingan atau analisis antara satu jurnal dengan jurnal lainnya dari berbagai sumber seperti referensi jurnal, buku teks dan e-book. Hasil : Hasil dari analisis ini menyatakan bahwa dalam menerapkan keselamatan pasien di rumah sakit, Kementerian Kesehatan Republik Indonesia telah menerbitkan Panduan Nasional yang terdiri dari 7 standar dan Panduan Nasional menganjurkan 7 Langkah Menuju Keselamatan Pasien Rumah Sakit. Kesimpulan : Dalam menerapkan keselamatan pasien Kementerian Kesehatan Republik Indonesia telah menerbitkan Panduan Nasional Keselamatan Pasien (Patient Safety) di Rumah Sakit tahun yang terdiri dari Standar Keselamatan Pasien Rumah Sakit dan Tujuh Langkah Menuju Keselamatan Pasien Rumah Sakit.
\end{abstract}

Kata Kunci : Penerapan, Sikap perawat, Langkah-langkah keselamatan pasien

\begin{abstract}
Background : Patient safety is something far more important in the implementation of patient safety measures and behavior with the ability of nurses is very important role in it. Purpose : The purpose of this paper is to identify the application of nurses' attitudes in implementing steps towards patient safety. Method : The method used is a literature review or a comparison or analysis of one journal with other journals from various sources such as journal references, textbooks and e-books. Results : The results of this analysis state that in implementing patient safety in hospitals, the Ministry of Health of the Republic of Indonesia has issued a National Guide consisting of 7 standards and a National Guide advocating 7 Steps Towards Hospital Patient Safety. Conclusion : In implementing patient safety the Ministry of Health of the Republic of Indonesia has issued a National Patient Safety Guide (Patient Safety) at the Hospital in the year which consists of Hospital Patient Safety Standards and Seven Steps Towards Hospital Patient Safety.
\end{abstract}

Keywords : Implementation, nurses' attitudes, patient safety measures 


\section{Latar Belakang}

Keselamatan

pasien merupakan sesuatu yang jauh lebih penting dalam pelaksanaan langkahlangkah keselamatan pasien dan perilaku dengan kemampuan perawat sangat berperan penting di dalamnya.

Keselamatan Pasien (Patient Safety) merupakan sesuatu yang jauh lebih penting dari pada sekedar efisiensi pelayanan. Perilaku perawat dengan kemampuan perawat sangat berperan penting dalam pelaksanaan keselamatan pasien. Perilaku yang tidak aman, lupa, kurangnya perhatian/motivasi, kecerobohan, tidak teliti dan kemampuan yang tidak memperdulikan dan menjaga keselamatan pasien berisiko untuk terjadinya kesalahan dan akan mengakibatkan cedera pada pasien, berupa Near Miss (Kejadian Nyaris Cedera/KNC) atau Adverse Event

(Kejadian

Tidak

Diharapkan/KTD) selanjutnya pengurangan kesalahan dapat dicapai dengan memodifikasi perilaku. Perawat harus melibatkan kognitif, afektif dan tindakan yang mengutamakan keselamatan pasien. (WHO, 2014).

Keselamatan pasien merupakan masalah keseahatan masyarakat global yang serius. Di Eropa mengalami pasien dengan resiko infeksi $83,5 \%$ dan bukti kesalahan medis menunjukkan 50-72,3\%. Di kumpulkan angka-angka penelitian rumah sakit di berbagai Negara, ditemukan KTD dengan rentang $3,2-16,6 \%$.

Secara keseluruhan program patient safety sudah diterapkan, namun masalah dilapangan merujuk pada konsep patient safety, karena walaupun sudah pernah mengikuti sosialisasi, tetapi masih ada pasien cedera, resiko jatuh, resiko salah pengobatan, pendelegasian yang tidak akurat saat oforan pasien yang mengakibatkan keselamatan pasien menjadi kurang maksimal (Bawelle, 2013.

Komisi Akreditasi Rumah Sakit (KARS) menyusun Standar Keselamatan Pasien. Rumah sakit harus merancang atau memperbaiki proses, memonitor dan mengevaluasi kinerja, menganalisis insiden secara intensif dan melakukan perubahan untuk meningkatkan kinerja serta keselamatan pasien. Proses perancangan tersebut harus mengacu pada "Tujuh Langkah Menuju Keselamatan Pasien Rumah Sakit" yang tertera pada Peraturan Menteri Kesehatan Republik Indonesia Nomor 1691 tahun 2011 tentang Keselamatan Pasien. 
Tujuh Langkah Menuju

Keselamatan Pasien merupakan acuan rumah sakit dalam melaksanakan program keselamatan pasien. Tujuh langkah tersebut adalah membangun kesadaran akan nilai keselamatan pasien, memimpin dan mendukung staf, mengintegrasikan aktivitas pelaporan risiko, mengembangkan sistem pelaporan, melibatkan dan berkomunikasi dengan pasien, belajar dan berbagi pengalaman tentang keselamatan pasien, serta mencegah cedera melalui implementasi sistem keselamatan pasien.

\section{Tujuan}

Tujuan penulisan ini yaitu
mengidenifikasi penerapan sikap
perawat dalam pelaksanaan langkah-
langkah meuju keselamatan pasien.

\section{Metode}

Metode yang digunakan merupakan literatur review atau suatu perbandingan atau analisis antara satu jurnal dengan jurnal lainnya dari berbagai sumber seperti referensi jurnal, buku teks dan e-book.

\section{Hasil \& Pembahasan}

1. Langkah pertama : Bangun Kesadaran Akan Nilai Keselamatan

\section{Pasien}

Berdasarkan wawancara mendalam, RSISA sudah melakukan upaya untuk membangun kesadaran dengan diberlakukannya sistem reward berupa uang bagi unit kerja yang melaporkan insiden hingga selesai, KMKP selalu mengingatkan tentang pelaporan insiden, distribusi formulir insiden ke unit kerja, sosialisasi saat orientasi karyawan baru, dan koordinasi tentang pelaporan antara unit kerja dan KMKP.

Kegiatan yang digalakkan sebatas pelaporan dan collecting data. RSISA sudah mendapatkan akreditasi, sehingga mindset yang ada adalah keselamatan pasien di RSISA sudah berjalan dan tinggal dilanjutkan saja, sehingga belum sampai di tahap memperbaiki atau meningkatkan sistem dan budaya keselamatan pasien kea rah yang lebih baik. Kesadaran untuk melakukan pengembangan ke arah perbaikan masih kurang. Bila tidak dilakukan upaya untuk meningkatkan kesadaran akan berdampak pada pelaksanaan keselamatan pasien yang hanya melaporkan terjadinya insiden, tetapi akan terus berulang untuk insiden yang sama karena tidak ada upaya pembelajaran, inisiatif, kepedulian dan keterpanggilan untuk melaksanakan 
pelayanan yang lebih baik dan mengutamakan keselamatan pasien. RSISA pernah melakukan survey penilaian keselamatan pasien sebanyak satu kali pada tahun 2009, namun tidak ada tindak lanjut yang berarti dari survey tersebut. Assessment hanya menggambarkan tingkat budaya pada satu waktu tertentu saja, sehingga assessment seharusnya dilakukan secara berkala untuk menilai perkembangannya. QLSC masih belum mengetahui atau familiar dengan Tujuh Langkah Menuju Keselamatan Pasien , karena belum ada panduan atau pedoman terkait Tujuh Langkah Menuju Keselamatan Pasien dan belum ada sosialisasi khusus tentang langkahlangkah tersebut.

Semenjak tahun 2014 belum dilaksanakan sosialisasi kembali tentang Tujuh Langkah Menuju Keselamatan Pasien yang berkaitan

dengan pencatatan, pelaporan, dan analisis akar masalah padahal sampai sekarang KMKP dan unit kerja masih mengeluhkan

pemahaman yang kurang dan pelaporan yang masih dianggap rumit.

2. Langkah ke dua : Pimpin dan Dukung Staf Anda
Kunjungan Monitoring lapangan ke unit kerja oleh Direksi dan KMKP belum dilakukan secara rutin, belum fokus pada keselamatan pasien, dan belum merata ke seluruh unit kerja. Untuk upaya mendemonstrasikan keselamatan pasien, pimpinan harus menyisihkan waktu satu jam dalam satu Minggu untuk mengunjungi unit kerja yang berbeda untuk membahas keselamatan pasien dan tata kelola klinis dengan staf. Belum ada pertemuan khusus untuk keselamatan pasien yang dilakukan. Sosialisasi mengenai Tujuh Langkah Menuju Keselamatan Pasien dilakukan satu kali pada tahun 2014 atau saat menjelang akreditasi.

\section{Langkah ke tiga: Integrasikan} Aktivitas Pengelolaan Risiko

Pengelolaan risiko yang terintegrasi adalah ketika risiko dan tindak lanjut yang dilakukan di suatu unit kerja dapat menjadi pembelajaran bagi unit kerja lain di rumah sakit.

Manajemen risiko di RSISA masih dalam tahap pelaporan, yaitu unit kerja mengidentifikasi risiko masing-masing, melakukan penilaian risiko dan melaporkannya kepada KMKP setiap tiga bulan sekali. Belum ada proses pembelajaran dari risiko yang terjadi di 
unit kerja. Pertemuan manajemen risiko yang seharusnya dilaksanakan tiga bulan sekali baru terlaksana satu tahun sekali karena kesibukan Ketua KMKP. Belum semua staf terlibat dalam mananajemen risiko. Belum semua unit melakukan Monitoring terhadap risiko di unit kerja masing-masing karena kurangnya pemahaman tentang manajemen risiko. Belum ada SOP terkait pelaksanaan manajemen risiko di RSISA. Masih banyak keterlambatan pelaporan dan bahkan banyak unit yang tidak melaporkan pelaporan manajemen risiko.

\section{Langkah ke empat: Kembangkan}

\section{Sistem Pelaporan}

Kesalahan nampak apabila para staf memiliki kesadaran untuk melaporkan setiap insiden yang terjadi dan tidak menutupi kejadian tersebut. Mekanisme pelaporan insiden baru dapat berjalan dengan baik apabila lingkungan kerja terbebas dari upaya saling menyalahkan.

Pelaporan insiden internal dari unit kerja ke KMKP dapat dilakukan melalui telepon terlebih dahulu atau langsung dengan formulir insiden. Untuk gading insiden hijau dan biru KMKP hanya menerima dan melakukan rekapitulasi pelaporan.
Sistem pelaporan yang dikembangkan oleh RSISA Semarang masih belum optimal. Masih banyak keterlambatan pelaporan insiden bulanan dari unit kerja. Banyak insiden yang tidak terlaporkan karena masih ada budaya menyalahkan dan menghukum di unit kerja. KMKP sudah melakukan sosialisasi agar tidak adanya blaming culture di RSISA, tapi hal tersebut belum dilaksanakan oleh seluruh unit kerja di RSISA yang berarti belum meratanya no bajing culture di RSISA Semarang. Hal ini didukung oleh penelitian tentang penurunan pelaporan insiden yang menyatakan bahwa adanya ketakutan disalahkan disebabkan oleh karena belum meratanya budaya keselamatan pasien di rumah sakit.

Laporan insiden dianggap beban karena rumit, kesibukan unit kerja membuat laporan tidak terjamah, pola pikir staf tidak perlu melaporkan insiden yang tidak menyebabkan cedera pada pasien, kurang peran aktif KMKP untuk membimbing penyelesaian pelaporan insiden, serta ada insiden yang terlambat diketahui. Untuk pelaporan insiden eksternal ke PERSI belum dilakukan secara rutin. KMKP pun belum pernah menerima feedback pelaporan dari PERSI. 
5. Langkah ke lima: Libatkan dan Berkomunikasi dengan Pasien

RSISA belum memiliki
kebijakan atau panduan terkait
mengkomunikasikan insiden kepada
pasien. Staf pun menjadi bingung
menentukan apa yang harus dilakukan,
apakah staf harus terbuka, atau pura-
pura tidak tahu. Rumah sakit perlu
melakukan medical error disclosure
atau pengungkapan kesalahan medis
dengan mempertimbangkan situasi dan
kondisi. Bersikap terbuka tentang apa
yang telah terjadi dan membahas
masalah segera, sepenuhnya dan penuh
kasih dapat membantu pasien mengatasi
dan menghadapi efek dari kesalahan
yang telah terjadi.

\section{Langkah ke enam: Belajar dan} Berbagi Pengalaman tentang

\section{Keselamatan Pasien}

Belajar dan berbagi pengalaman tentang keselamatan pasien dilakukan dengan berdikusi saat rapat ruangan. Analisis akar masalah dilakukan dengan metode RCA untuk insiden yang mempunyai grade kuning atau merah. RCA melibatkan KMKP dan pihak yang terlibat dalam insiden dan unit kerja yang mengalami insiden. Hasil RCA belum disebarluaskan ke seluruh unit kerja Tedapat beberapa kendala yaitu sulit mengumpulkan pihakpihak yang terlibat dalam insiden di satu waktu, serta memerlukan proses tindak lanjut yang memakan waktu lama terutama untuk penyelesaian kasus yang memerlukan biaya yang cukup besar sehingga pelaksanaan RCA melebihi dari batas waktu.

\section{Langkah ke tujuh: Cegah Cedera}

\section{Melalui Implementasi Sistem}

\section{Keselamatan Pasien}

Belum ada pembelajaran insiden secara aktif dan melibatkan seluruh unit kerja. Hanya ada penyampaian jumlah insiden saat rapat pimpinan tiga bulanan. Penyebar luasan informasi judul insiden dan tindak lanjut insiden melalui IT Blog rumah sakit belum rutin dilakukan.

Dalam mencegah cedera RSISA menggunakan metode FMEA yang dilakukan satu tahun sekali. KMKP memprioritaskan risiko di unit kerja yang akan dilakukan redesign. Risiko yang diprioritaskan adalah risiko dengan grading tinggi sampai sangat tinggi.

Dalam pelaksanaan FMEA masih terdapat kendala, yaitu pelaksanaannya memerlukan dana yang besar sehingga harus dilakukan bertahap dan memerlukan waktu yang lama, 
birokrasi yang panjang, pelaksanaan sering bentrok dengan program rumah sakit yang lain, dan vacuumnya pertemuan manajemen risiko.

\section{Sumber Daya Manusia dalam} Pelaksanaan Tujuh Langkah Menuju Keselamatan Pasien

Ketua KMKP dan Wakil Ketua KMKP juga menjabat di bagian lain, sehingga tidak bisa secara penuh menjalankan tugasnya di KMKP. Jumlah anggota KMKP dan QLSC di unit kerja dirasa cukup, namun harus selalu diimbangi dengan refresh secara berkala kepada staf. Belum semua anggota KMKP mengikuti pelatihan RCA dan FMEA.

Tidak ada pelatihan khusus tentang Tujuh Langkah Menuju Keselamatan Pasien. Hanya ada sosialisasi pada tahun 2014 saat menjelang akreditasi dan tidak ada pengukuran efektivitas dari sosialisasi tersebut.

\section{Ketersediaan Dana dalam}

\section{Pelaksanaan Tujuh Langkah}

\section{Menuju Keselamatan Pasien}

Dana terkait Tujuh Langkah Menuju Keselamatan Pasien disusun oleh KMKP satu tahun sekali, dan diusulkan kepada Direksi. Dana yang tersedia sudah cukup bahkan berlebih.
Pasalnya tahun ini KMKP bisa dikatakan vacuum, sehingga tidak terlalu banyak kegiatan yag dilaksanakan.

\section{Sarana dan Prasarana}

Komputer di unit kerja dinilai belum cukup dan belum layak sehingga menghambat pelaksanaan dan pencatatan dan pelaporan.

Belum ada sarana teknologi informasi yang terintegrasi di rumah sakit sehingga menjadi kendala dalam pelaporan insiden di unit kerja.

Ketika ada insiden maka unit kerja harus mencatat nomor rekam medis pasien, waktu dan tanggal insiden tersebut terjadi, perawat yang melakukan kontak dengan pasien, dan sebagainya. Saat ini hal tersebut harus dilakukan dengan cara manual, sehingga untuk melihat rekam medis pasien, unit kerja harus pergi ke rekam medis untuk melihat nomornya. Padahal unit kerja sudah merasa sibuk dengan tugas pokoknya di unit masing-masing. Untuk waktu dan tanggal insiden terjadi pun unit kerja sering kali lupa karena tidak ada sistem komputer yang mencatat. Hal ini akhirnya menyebabkan unit malas melaporkan insiden, keterlambatan pelaporan 
insiden, dan tidak lengkapnya data di formulir insiden.

\section{Kebijakan dan SOP dalam}

Pelaksanaan Tujuh Langkah Menuju

Keselamatan Pasien

RSISA belum memiliki dokumen yang menjelaskan tentang petunjuk pelaksanaan Tujuh Langkah Menuju Keselamatan Pasien, sehingga staf pun masih kurang familiar. Namun RSISA sudah memiliki panduan terkait poinpoin yang ada di dalam Tujuh Langkah Menuju Keselamatan Pasien; seperti RCA, FMEA, pencatatan dan pelaporan insiden.

\section{Penutup}

\section{Kesimpulan}

Berdasarkan hasil penelitian, belum semua langkah dalam 'Tujuh Langkah Menuju Keselamatan Pasien' dilakukan oleh RSISA terutama untuk langkah ke lima, yaitu komunikasi terbuka kepada pasien dan keluarga tentang insiden. Sudah dilakukan berbagai upaya untuk mencapai langkah yang lain, namun upaya yang dilakukan masih belum optimal.

\section{Saran}

Tim KMKP diharap turun lapangan apabila terjadi KTD dan insiden sentinel, serta membimbing unit kerja dalam proses penyelesaian laporan insiden.

Tim KMKP dan Direksi diharap melakukan dialog khusus secara rutin tentang keselamatan pasien dengan staf dalam rangka menunjukkan komitmen dan mempromosikan keselamatan pasien; meningkatkan kesadaran, serta membangun budaya terbuka dan adil

Melaksanakan sosialisasi secara rutin untuk meningkatkan pemahaman seluruh staf.

$$
\text { Melaksanakan pertemuan }
$$
khusus yang membahas tentang pembelajaran insiden yang pernah terjadi dan isu keselamatan pasien untuk mencegah insiden yang sama terulang kembali, meningkatkan

kesadaran, membangun budaya terbuka, adil, dan no blaming.

Perlu dibuat dokumen yang memuat tentang petunjuk pelaksanaan Tujuh Langkah Menuju Keselamatan Pasien di RSISA

Perlu dibuat panduan yang memuat etika serta cara berkomunikasi dengan pasien dan keluarga apabila terjadi

insiden.

Perlu dibuat SOP terkait pelaksanaan manajemen risiko di RSISA. 
Perlu dibuat sistem teknologi informasi yang terintegrasi di rumah sakit untuk memudahkan pencatatan dan pelaporan.

\section{Daftar Pustaka}

Bawelle, (2013). Jurnal Hubungan Pengetahuan dan Sikap Perawat dengan Pelaksanaan Keselamatan Pasien (Patient Safety) di Ruang Rawat Inap RSUD Liun Kandage Tahuna. Program Studi Ilmu Keperawatan Fakultas Kedokteran Universitas Sam Ratulangi, ejournal keperawatan (e-Kp), Manado.

Cahyono, Suharjo. (2008) Membangun

Budaya Keselamatan Pasien dalam Praktik Kedokteran. Yogyakarta : Kanisius

Dewi,Mursidah. (2012). Pengaruh Pelatihan Timbang Terima Pasien Terhadap Penerapan Keselamatan Pasien Oleh Perawat Pelaksana Di RSUD Raden Mattaher Jambi.Jurnal Health \& Suport.5,(3):647:652.

Iskandar, Heru, Halimi Maksum, dan Nafisah. (2014). Faktor Penyebab Penurunan Pelaporan Insiden Keselamatan Pasien Rumah Sakit. Malang : Fakultas Kedokteran Universitas Brawijaya Malang,
2014 Nugroho, $\quad$ SriH.P., Sujianto,U. Supervisi Kepala Ruang Model Proctor Untuk Meningkatkan Pelaksanaan Keselamatan Pasien. Jurnal Keperawatan Indonesia.20, (1):56-64

Notoatmodjo, S. (2003). Pendidikan dan Perilaku Kesehatan. Jakarta : PT. Rineka Cipta.

Potter \& Perry, (2005). Buku Ajar Fundamental Keperawatan : Konsep, Proses, dan Praktik. Edisi 4. Jakarta : EGC.

Rahayu, Sri. (2011). Pengembangan Program Patient Safety Berdasarkan Awareness dan Komitmen Individu. RSUD Ibnu Sina Kabupaten Gresik

Rachmawati, Alifa Rizqia, dkk. (2017). ANALISIS PELAKSANAAN TUJUH LANGKAH MENUJU KESELAMATAN PASIEN DI RUMAH SAKIT ISLAM SULTAN AGUNG SEMARANG. JURNAL KESEHATAN MASYARAKAT (e-Journal) Volume 5, Nomor 1 (ISSN: 2356-3346)

R.H, Simamora. (2019). Buku Ajar Pelaksanaan Identifikasi Pasien. Uwais Inspirasi Indonesia 
R.H, Simamora. (2019). Documentation Of Patient Identification Into The Electronic System To Improve The Quality Of Nursing Services. International Jurnal Of Sciensific \& Technology

R.H, Simamora. (2019). The Influence Of Training Handover Based SBAR Communication For Improving Patients Safety. Indian Journal Of Public Health Research \& Deveropment.

Utami, Yuni Wulan \& Supratman. (2009). HUBUNGAN ANTARA PENGETAHUAN DENGAN SIKAP PERAWAT DALAM PEMENUHAN KEBUTUHAN SPIRITUAL PASIEN DI BRSUD SUKOHARJO. Berita Ilmu Keperawatan ISSN 1979-2697, Vol. 2 No. 2 : 69-74

Widajat, Rochmanadji. (2009). Being a Great and Sustainable Hospital. Jakarta : PT Gramedia Pustaka Utama

Yusuf, Muhammad. (2017). Penerapan Patient Safety Di Ruang Rawat Inap Rumah Sakit Umum Daerah Dr.Zainoel Abidin.Jurnal Ilmu Keperawatan. 5,(1):85-88. 